\title{
Effect of ultrasonic cavitation on the wetting and reaction of $\mathrm{Al}-\mathrm{Ti} / \mathrm{C}$ interface
}

\author{
Li Y. L. ${ }^{1, a^{*}}$, He L. Z. ${ }^{2, b}$, Zhao J. T., a \\ ${ }^{1}$ School of Materials Science and Engineering, Northeastern University, \\ Shenyang 110004, P. R. China \\ ${ }^{2}$ Key Lab of Electromagnetic Processing of Materials, Ministry of Education, Northeastern University, \\ Shenyang 110004, P. R. China \\ aliyl@smm.neu.edu.cn
}

Keywords: Al-Ti-C grain refinement, $\mathrm{Al}-\mathrm{Ti} / \mathrm{C}$ interface, acoustic cavitation, wetting and reaction

\begin{abstract}
Al-Ti-C alloy is a kind of fine refinement agent. However, the wetting of $\mathrm{Al} / \mathrm{C}$ interface and $\mathrm{TiC}$ synthesis are the key technical problems to be solved in the preparation of Al-Ti-C grain refinement. In this paper, the acoustic cavitation effect was used to improve the wettability of $\mathrm{Al}-\mathrm{Ti} / \mathrm{C}$ interface, and improve the thermodynamic conditions of reaction, and thus the Al-Ti-C grain refinement agent was successfully prepared. The wetting properties of Al-Ti/C interface under different conditions were obtained. The results show that the acoustic cavitation effect significantly influences the wetting process. When the sound intensity is greater than the threshold value, the acoustic cavitation effect produces, and then the complete wetting of $\mathrm{Al}-\mathrm{Ti} / \mathrm{C}$ interface can be realized. At the same time, the high temperature effect of the cavitation also prevents the formation of harmful Al4C3 compound, and changes the way of forming TiC compound which is different from the conventional reaction, and enhances the thermodynamics reactivity of the system to promote the TiC synthesis.
\end{abstract}

\section{Introduction}

$\mathrm{Al}-\mathrm{Ti}-\mathrm{C}$ is a kind of grain refinement for aluminum and its alloys. Compared with Al-Ti-B grain refinemnt, the aggregation tendency of $\mathrm{TiC}$ particle is less than that of $\mathrm{TiB}_{2}$ particle, and also has better grain refinement effect for aluminum alloy with $\mathrm{Zr}(0.03 \mathrm{wt}, \%), \mathrm{Cr}$ and $\mathrm{Mn}$. Thus, AlTiC is a new generation of grain refinement materials, as a replacement of AlTiB [1-3].

However, in the synthetic process of Al-Ti-C grain refiner, the $\mathrm{C}$ powders adsorb gas and other impurities due to the poor wettability between $\mathrm{C}$ (graphite) and $\mathrm{Al}$ melt [4], and they gather into a mass because of the easy formation of hydrogen bond, and thus it is difficult for Al melt to wet inner $\mathrm{C}$ powders and react. Meanwhile, the $\mathrm{C}$ powders are easy to float on the surface of $\mathrm{Al}$ melt, and the redox reaction happens when they contact with air, the formation of oxide film at the surface of $\mathrm{Al}$ melt hinders the wetting and reaction, thus prevents $\mathrm{C}$ and Al-Ti melt to synthesize $\mathrm{TiC}$ [5]. The liquid/solid interface reaction is usually transferred by reactants to the interface, and accompanies by the interface adsorption, activation, and desorption of reaction products from interface process of continuous cycle. For the $\mathrm{Al} / \mathrm{C}$ interface system, the wetting of $\mathrm{Al} / \mathrm{C}$ is a prerequisite for the interfacial reaction, which is also the base of $\mathrm{TiC}$ synthesis. At the same time, the generated $\mathrm{TiC}$ can desorption from interface, and the realization of $\mathrm{Al} / \mathrm{C}$ interfacial mass transfer is a kinetics factor of reaction. Therefore, the key technology of Al-Ti-C grain refinement is to improve the wettability of $\mathrm{Al} / \mathrm{C}$ interface and enhance the efficiency of mass transfer.

High intensity ultrasound has the acoustic cavitation effect and acoustic streaming effect [6], it can change the mass transfer behavior of molten metal, and be used for metal melt purification, degassing and grain refining, ect. [7-9]. It can also enhance the wettability between molten metal and nucleation ability, and thus improves the strengthening effect and migration of particle. The external energy gained from ultrasound make particle release from clusters and distribute dispersedly. Therefore, the effects of acoustic cavitation and acoustic streaming are suitable for the 
preparation of high performance AlTiC grain refinement [10, 11].

By coupling high density ultrasound into aluminum melt, the wettability of Al-Ti/C interface is improved by the formation of cavitation effect in aluminum melt, and thus the interfacial mass transfer is enhanced. At the base of successful preparation of Al-Ti-C grain refinement, the wetting kinetic curve was drawn, and the relation between interfacial wetting and acoustic cavitation and interface reaction mechanism were also investigated. The acoustic coupling parameters were optimized to further verify the melt reaction mechanism during the preparation process of Al-Ti-C grain refinement under ultrasonic field coupling effect.

\section{Materials and Equipment}

Al-5wt.\% Ti alloy was prepared by liquid solid reaction method, using $\mathrm{K}_{2} \mathrm{TiF}_{6}$ (purity, 99.8, wt.\%) and pure $1075 \mathrm{Al}$ at the reaction temperature of $800{ }^{\circ} \mathrm{C}$ and the reaction time of $30 \mathrm{~min}$.

The ultrasonic field coupling system is composed of the ultrasonic generator, transducer, amplituder, graphite crucible and argon device. Fig. 1 is the structure and principle diagram of this system. The ultrasonic generator excites the transducer to generate ultrasonic vibration, and the amplitude is enlarged by amplituder, and then the ultrasonic energy is directly coupled into Al-5 Ti alloy melt, significantly improves the coupling efficiency of ultrasonic wave in metal melt. The graphite crucible is placed at outer edge of amplitude transformer. Therefore, the Al-Ti /C interface wetting experiment system under ultrasonic field coupling was built.

The ultrasonic generator is designed for automatic frequency tracking to reduce the fluctuation of system resonance frequency caused by the change of melt temperature. The frequency of the ultrasonic generator is $20 \mathrm{kHz}$, the adjusting range is $\pm 500 \mathrm{~Hz}$, the maximum electric power is $200 \mathrm{~W}$, the sound / electric efficiency of system is about $75 \%$.

The recycled water was used to cool the amplituder. There is an argon inlet at the lower part of heating furnace. When the flow is relatively small, argon can be used as protective gas for Al-Ti melt, and it can cool the graphite crucible, and the Al-Ti /C interfacial wetting specimen as casting state was obtained when the flow is large.

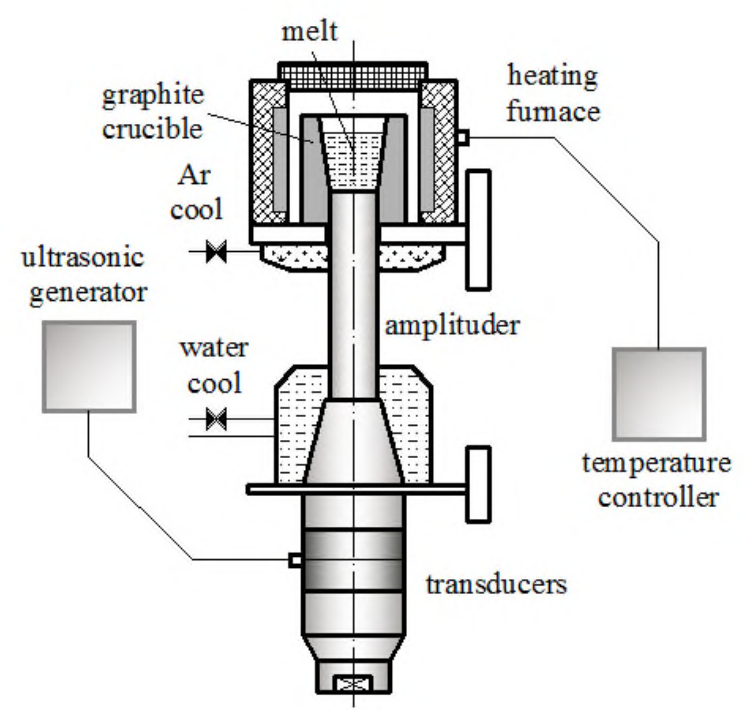

Fig. 1 Schematic diagram of experimental setup.

\section{Experiment Procedure}

The Al-Ti melt with eight grams was poured into graphite crucible, and argon was used as protective gas, the heating temperature is $700{ }^{\circ} \mathrm{C}$, and then the acoustic intensity of $11 \mathrm{w} / \mathrm{cm}^{2}$ was applied into Al-Ti melt for the ultrasonic field coupling processing, the acoustic cavitation and acoustic streaming effects of ultrasound promote the interfacial wetting and reaction between $\mathrm{C}$ and 
Al-Ti melt. When the holding time was 10 minutes, the ultrasound and temperature controllers were closed, the graphite crucible was cooled by argon blowing, and the Al-Ti /C interfacial wetting specimen as casting state was obtained. The longitudinal section of specimen was observed under the optical microscope and scanning electron microscope to study the ultrasonic field coupling effect on $\mathrm{Al}-\mathrm{Ti} / \mathrm{C}$ interfacial wettability and reactions.

\section{Results and Discussion}

The Al-Ti /C interfacial wetting under ultrasonic field coupling effect.

Fig. 2(a) shows the Al-Ti/C interfacial wetting photos under the ultrasonic field coupling effect with intensity of $11 \mathrm{w} / \mathrm{cm}^{2}$. It can be seen that the Al-Ti melt climbs on the side wall of graphite crucible, and the stable wetting angle between melt and the side wall is close to 0 degree. Without the ultrasonic effect, no wetting phenomenon occurs between Al-Ti melt and graphite, Al-Ti melt exhibits sphere obviously under the melt surface tension (Fig. 2(a)). The complete interfacial wetting between Al-Ti melt and graphite is realized under high intensity ultrasonic field coupling effect.

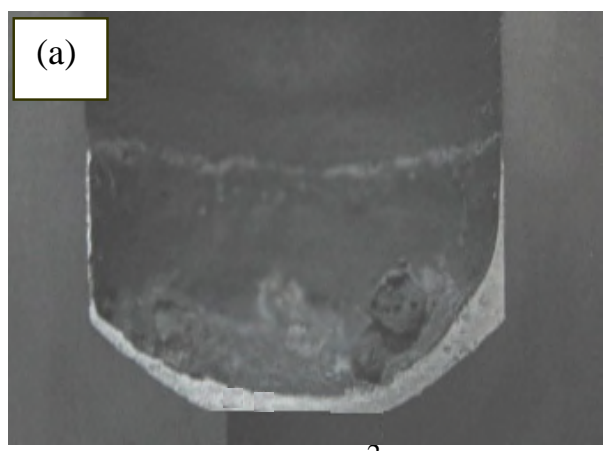

(a) $11 \mathrm{w} / \mathrm{cm}^{2}$

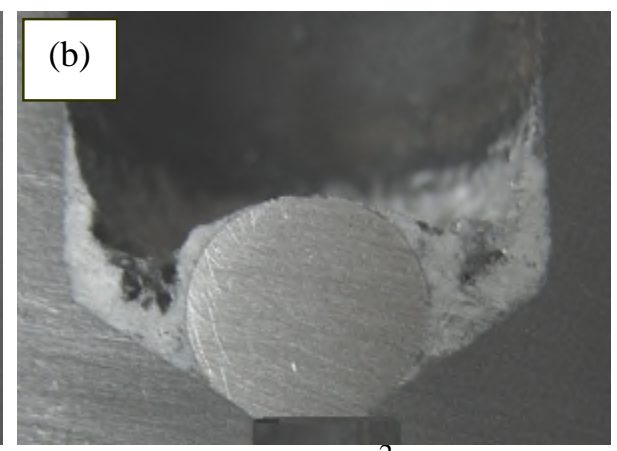

(b) $0 \mathrm{w} / \mathrm{cm}^{2}$

Fig. 2 The Al-Ti/C interfacial wetting photos under the ultrasonic field coupling effect.

In order to evaluate effect of ultrasonic intensity on the steady-state wetting angle between Al-Ti melt and graphite interface, the ultrasonic field coupling intensity of 0 and $1,3,4,6,8 \mathrm{~W} / \mathrm{cm}^{2}$ were applied for two minutes, cooled by argon blowing. The steady-state wetting angle was measured and the wetting kinetic curve is illustrated in Fig. 3. The steady-state wetting angle decreases slightly with increasing sound intensity firstly. A quick decrease is observed when the sound intensity exceeds $4.0 \mathrm{w} / \mathrm{cm}^{2}$. It tends to $0^{\circ}$ when the sound intensity is higher than $4.5 \mathrm{w} / \mathrm{cm}^{2}$, indicating the complete wetting between the Al-Ti melt and graphite interface. According to this curve, the corresponding sound intensity value is $4.25 \mathrm{w} / \mathrm{cm}^{2}$ when the steady wetting angle is $90^{\circ}$, which is called as the wetting transition sound intensity.

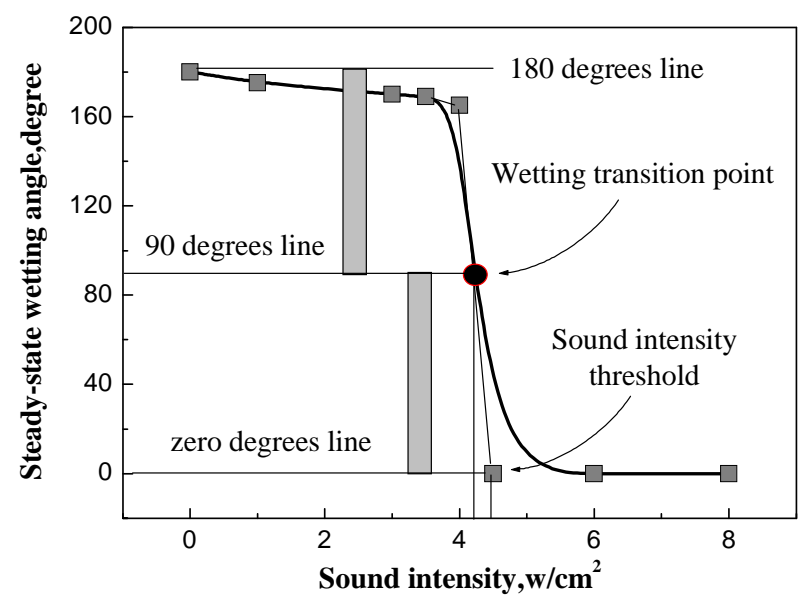

Fig. 3 The wetting kinetic curve of Al-Ti /C interface. 
It can be seen that an acoustic intensity threshold exists in the wetting process between Al-Ti melt and $\mathrm{C}$. The steady-state wetting angle tends to $0^{\circ}$ after the sound intensity threshold reaches, which indicates that the wetting process of $\mathrm{Al}-\mathrm{Ti} / \mathrm{C}$ interface under the ultrasonic coupling is related to the ultrasonic cavitation.

The microstructures of $\mathrm{Al}-\mathrm{Ti} / \mathrm{C}$ interface and forming mechanism under field coupling effect.

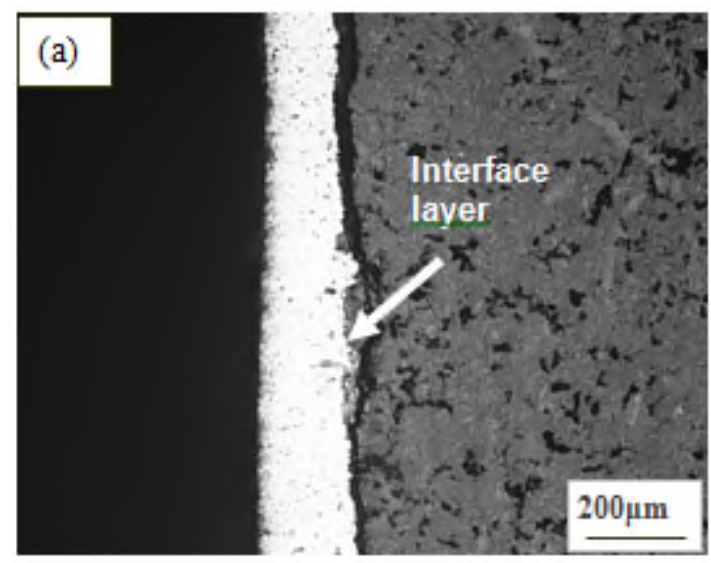

(a) interface layer

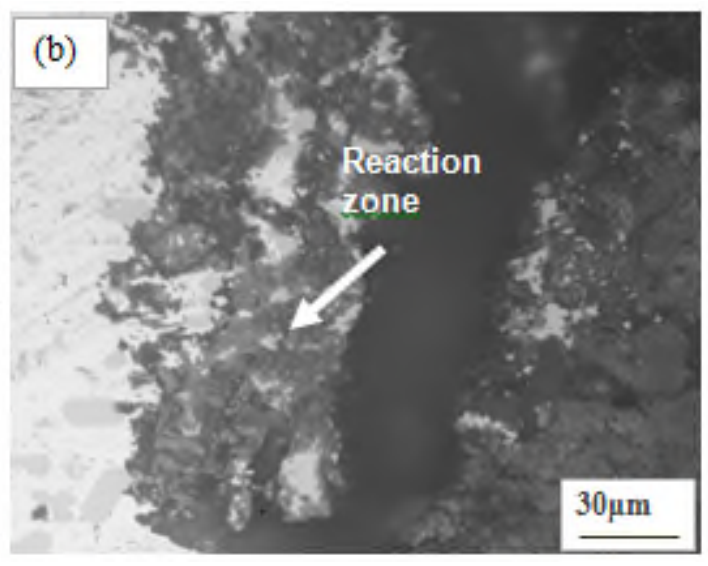

(b) reaction zone

Fig.4. The microstructures of interface layer and reaction zone of Al-Ti/C.

At the wetting interface of molten aluminum and graphite under high intensity ultrasonic coupling, the interface layer appears (Fig. 4 (a)), and the aluminum melt infiltrates into the graphite substrate, forming a reaction zone (Fig. 4(b)). DES analysis shows that a large number of $\mathrm{TiAl}_{3}$ and $\mathrm{TiC}$ form in the reaction zone.

The forming process of $\mathrm{TiC}$ phase is as follows:

According to thermodynamic conditions, the reaction of graphite becoming free $\mathrm{C}$ atom and the Gibbs free energy (G, KJ/mol) can be expressed by [12]:

$$
\begin{aligned}
& C(S) C \rightarrow C \\
& \Delta G_{1}^{\circ}=71431-45.970 T
\end{aligned}
$$

It can be seen that the reaction (1) can occur when the temperature is higher than $1280{ }^{\circ} \mathrm{C}$, that is, $\mathrm{C}$ can be a free $\mathrm{C}$ atom in $\mathrm{Al}$ melt.

The reaction to form $\mathrm{Al}_{4} \mathrm{C}_{3}$ between graphite and $\mathrm{Al}$ melt and the Gibbs free energy $(\mathrm{G}, \mathrm{KJ} / \mathrm{mol})$ can be expressed by [12]:

$$
\begin{aligned}
& C+A l(L)=A l_{4} C_{3} \\
& \Delta G_{2}^{\circ}=-89611+32.841 T \\
& C(S)+A l(L)=A l_{4} C_{3} \\
& \Delta G_{3}^{\circ}=-161042+78.811 T
\end{aligned}
$$

By formula (4) and (6), when the temperature is higher than $2455{ }^{\circ} \mathrm{C}, \triangle G$ is positive, the reactions (3) and (5) cannot thermodynamically, that is, the harmful compounds $\mathrm{Al}_{4} \mathrm{C}_{3}$ can not form under the Al-Ti/C wetting condition, which can be confirmed in Fig. 3 (b).

Under the ultrasonic field coupling effect, the incident and reflection sound waves acoustic wave at the $\mathrm{Al}-\mathrm{Ti} / \mathrm{C}$ interface have superimposition effect [11], the high temperature in the melt near the interface $\mathrm{Al}-\mathrm{Ti} / \mathrm{C}$ will produce locally, which can make $\mathrm{C}$ a free $\mathrm{C}$ atom in $\mathrm{Al}$ melt, and also can effectively prevent the formation of $\mathrm{Al}_{4} \mathrm{C}_{3}$ directly. The formation of $\mathrm{TiC}$ can be expressed by:

$$
T i+C(S)=T i C
$$




$$
T i+C=T i C
$$

Therefore, the wetting of Al-Ti/C interface can achieve under the ultrasonic field coupling effect [13], the formation of $\mathrm{C}$ atoms prevents the formation of $\mathrm{Al}_{4} \mathrm{C}_{3}$, changes the way to form $\mathrm{TiC}$, enhances the system reactivity, promotes the TiC synthesis, and improves the reaction efficiency.

Usually, the combination of $\mathrm{Ti}$ and $\mathrm{C}$ needs to be at higher temperature, the high density ultrasonic coupling effect changes the reaction way, reduces the reaction activation energy, and promotes the formation of $\mathrm{TiC}[10]$ at lower temperature [10].

\section{Conclusion}

The cavitation effect in the aluminum melt generated high intensity ultrasonic coupling can significantly improve the wettability of the Al-Ti/C interface. When the sound intensity is greater than the threshold value, the complete wetting of the $\mathrm{Al}-\mathrm{Ti} / \mathrm{C}$ interface can realize, the steady-state wetting angle close to $0^{\circ}$, and make Al-Ti melt infiltrate into the internal $\mathrm{C}$ powder and react. The cavitation effect produces high temperature in the melt near the Al-Ti/C interface locally, can make $\mathrm{C}$ a free $\mathrm{C}$ atom in $\mathrm{Al}$ melt, and can effectively prevent the formation of $\mathrm{Al}_{4} \mathrm{C}_{3} \mathrm{C}$ directly. The formation of $\mathrm{TiC}$ can be expressed by: $T i+C(S)=T i C, T i+C=T i C$. The Al-Ti-C alloy can form at lower temperature. The optimized sound intensity of interface wetting and reaction is greater than $4.25 \mathrm{w} / \mathrm{cm}^{2}$.

\section{Acknowledgement}

This work was supported by the National Natural Science Foundation of China (No. 11574043,51174061).

\section{References}

[1] D. Qiu, J. A. Taylor, M. X. Zhang, Understanding the co-poisoning effect of Zr and Ti on the grain refinement of cast aluminum alloys, Mater. Sci. Eng. A, 41A (2010) 3412-3421.

[2] L. Yu, X. F. Liu, Z. Q. Wang, X. F. Bian. Grain refinement of A356 alloy by AlTiC/AlTiB master alloys, J. Mater. Sci. (40) (2005) 3865-3867.

[3] P. Moldovan, G. Popescu. The grain refinement of 6063 aluminum using Al-5Ti-1B and Al-3Ti-0.15C grain refiners, Aluminum Alloy. (12) (2004) 59-61.

[4] N. Eustathopoulos, J. C. Joud, P. Desre, J. M. Hicter. The wetting of carbon by aluminum and aluminum alloys, J. Mater. Sci. (9) (1974) 1233-1242.

[5] Y. V. Naidich, Y. N. Chubashov, Observation carbon dissolve in Al alloy, Metallur. (3) (1983) 67-75.

[6] G. I. Eskin, Principles of ultrasonic treatment: application for light alloys. Adv. Perform. Mater. (4) (1997) 223-232.

[7] G. I. Eskin, Improvement of the structure and properties of ingots and worked aluminum alloy semifinished products by melt ultrasonic treatment in a cavitation regime, Metallur. 54(7-8) (2010) 319-325.

[8] H. B. Xu, Q. Y. Han, T. T. Meek, Effects of ultrasonic vibration on degassing of aluminum alloys, Mater. Sci. Eng. A, (473) (2008) 96-104.

[9] H. S. Liu, X. Qiao, Z. H. Chen, R. P. Jiang, X. Q. Li. Effect of ultrasonic vibration during casting on microstructures and properties of 7050 aluminum alloy, J. Mater. Sci. 46 (2011) 3923.

[10] Y. L. Li, F. R. Cao, Y. B. Chen, H. K. Feng. Ultrasonic couple processing: a novel technique for fabrication of metal matrix surface composites, Metallur. Mater. Trans. A, 40A (2009) 
2178-2183.

[11]Y. L. Li, H. K. Feng, F. R. Cao, Y. B. Chen. Al-Ti-C grain refiner made by ultrasonic levitation, J. Wuhan University of Technology-Materials Science Edition, 3(23) (2008) 319 -322.

[12]A. R. Roberta, X. J. Zheng. Thermodynamic consideration of grain refinement of aluminum alloys by titanium and carbon. Metallur. Trans. A, (2A) (1991) 3071-3075.

[13] Y. L. Li, T. G. Zhou. Achieving Al melt/carbon and Al-Ti melts/carbon interfaces wetting via ultrasonic couple processing. Metallur. Mater. Trans. A, (44) (2013) 3337-3343. 